\title{
Whether you know it or not; applied Research is the Boss
}

\author{
Thobias Sarbunan \\ Institut Agama Kristen Negeri Ambon \\ https://orcid.org/0000-0001-8236-370X
}

\begin{abstract}
Science was required to develop mankind more compassionate. The research method is a sort of practical philosophy that seeks to establish a flexible path between the cosmos and its surrounds, as well as the living phase. The purpose of applied research is to solve difficulties in order to establish and offer more quantifiable outcomes. The goal of this article is to raise knowledge of practical research methodologies related to COVID-19 and its unforeseen scenarios, as well as the virus's spread and influence on human life and the environment. As a result of extensive exposure to applied research methodologies, the author is concerned about the future comprehensive development of all areas of science.
\end{abstract}

Keyword: Applied Research, Prior Knowledge, Paradigms, Practical

\section{Introduction}

The COVID-19 situation is compounded with a broad range of problems, and society is seeking to go beyond knowledge in order to sustain human existence. Learning about applied research has several benefits that may be used across a range of subjects of study. Read the full article on how to take action through this article.

\section{Discussion}

Khan (2021) underlines "applied investigation may be kinds of examination arrange that looks to handle a specific issue or grant inventive answers for issues. It is regularly implied to as a coherent strategy, methodologies to standard issues, and ordinarily a consequent examination arrange that assist explores" (para. 1). Subsequently, based on the author understanding applied research can be categorized into three primary parts of the strategy as takes after: "evaluation, activity investigate, and research development" (para. 2). And the case or research focus of applied research can be determined, for example, "improving farming harvest creation; treating or curing a specific illness; increasing the energy productivity of homes, workplaces, or modes of transportation; recommending innovative and adapted inference strategies in a specific inquiry" (para. 3).

Here below is a list of subcategories of applied research that will perhaps be developed following examining the structure of applied research in general:

It has a wide range of applications, from applied conduct analysis to city planning and public policy, as well as program assessment. Applied research may be done in a variety of methods, including entirely quantitative, entirely subjective, or a blended strategy study plan that includes both quantitative and subjective data pieces in a single project. All of the countless parts in applied research projects have one thing in common: the tradition of guiding investigation in "non-pure" research contexts since information is intended to help in solving a real problem. (para. 4)

The nature of applied research, according to prior studies, is as follows: 
Although there is applied research accessible, basic research is hypothesis-driven. Applied research is action that is planned and carried out, whereas fundamental research is logical and perceptive. In contrast to basic research, which focuses on gathering data rather than addressing current difficulties, applied research assists organizations and individuals in overcoming specific challenges. (para. 5)

According to Blog, "applied research" is "research focused on providing answers to specific problems in order to provide a solution to a defined problem" $(2022, \mathrm{p} .1)$. The following is a list of further alerts:

Applied research is frequently seen as a non-systematic examination because of its direct process to find a solution to a problem. It's a form of follow-up research that delves further into the findings of pure or basic research in order to validate findings and apply it to new solutions. (para. 4)

Multiple fields, including education, have previously been mentioned in the literature as conducting applied research. The following is an example of five disciplines: first, the business field. Applied research is used in business to produce product solutions and acquire expertise; it allows firms to discover the unique demands of target audiences." Additionally, popular keywords to identify while applying another level of study are "to improve (organization recruitment process, workplace efficiency, and organizational policy) as well as to bridge (skills gap in the workplace)."

Second, applied research is utilized in the realm of education to "test pedagogic processes, educational policies, and pragmatic problem-solving solutions." ARiE's nature may be divided into four categories: In the following examples, such as a study to improve teacherlearner classroom engagements; and (...) a school's readiness for its students; and (...) a study to build students' interests in (...)." Third, "it is a laboratory procedure of investigation since it uses current scientific information to real circumstances," related to the science field. It has impact on a wide range of sectors." Then, in the realm of science, the terminology to lead is "to enhance and to treat."

Fourth, refer to the psychology field, "most industrial-psychologists engaged in workplace behaviour, human resources, and organizational development mix psychological principles with practical research to deliver answers." Considering the perspective of psychology research design, the respective example explains how to perform applied research: "to design genuine worker incentive strategies in order to improve workplace commitment." Anxiety and panic crisis therapy and management options, as well as features that improve worker productivity, are being investigated." Fifth, in the medical field, as shows:

In health and medical sciences, applied research serves as the background to evidencebased and solution-oriented medicine." The adaptation of applied research to medicine is referred to as \{ HYPERLINK "https://www.ntnu.edu/mh/akf/forskning" $\mathrm{l}$ \} to measure the extent to which the findings of basic or pure research can be adopted or modified into a solution-oriented approach. (Blog, 2022, para. 16)

Concepts that represent the framework of applied research in health studies, as expressed towards the goal of implementation, including "an inquiry to locate the therapeutic qualities of a certain herb; secondly, an investigation to detect the bad consequences of using a specific drug." Additional references will expand understanding on extended examples of applied 
research issues that may be taught and used to a wide range of study disciplines, as indicated by the following article. ${ }^{1}$

In applied research, researchers examine how well they use their knowledge to construct a system and solve an urgent problem while also providing predictable outcomes. The term "applied research" comes from Edgar et al. (2017), who defined it as the stage in the research life cycle when investigators examine how successful they are at using their knowledge in solving urgent problems. As a result, applied research has the following features, according to this researcher:

Applied research is a process to rigorously understand and quantify how effective an engineered system is at solving the problem for which it was designed. The key distinction is a preconceived "problem" that needs "solving." Applied research includes designing, implementing, and testing systems. (p. 63)

Social applied research can be done on a wide range of subjects ranging from epidemiological, survey, and ethnography to program staff, beneficiaries, and community stakeholders. Bickman \& Rog (2009) explain that evaluation is justified as one of the method preferences for social applied research.

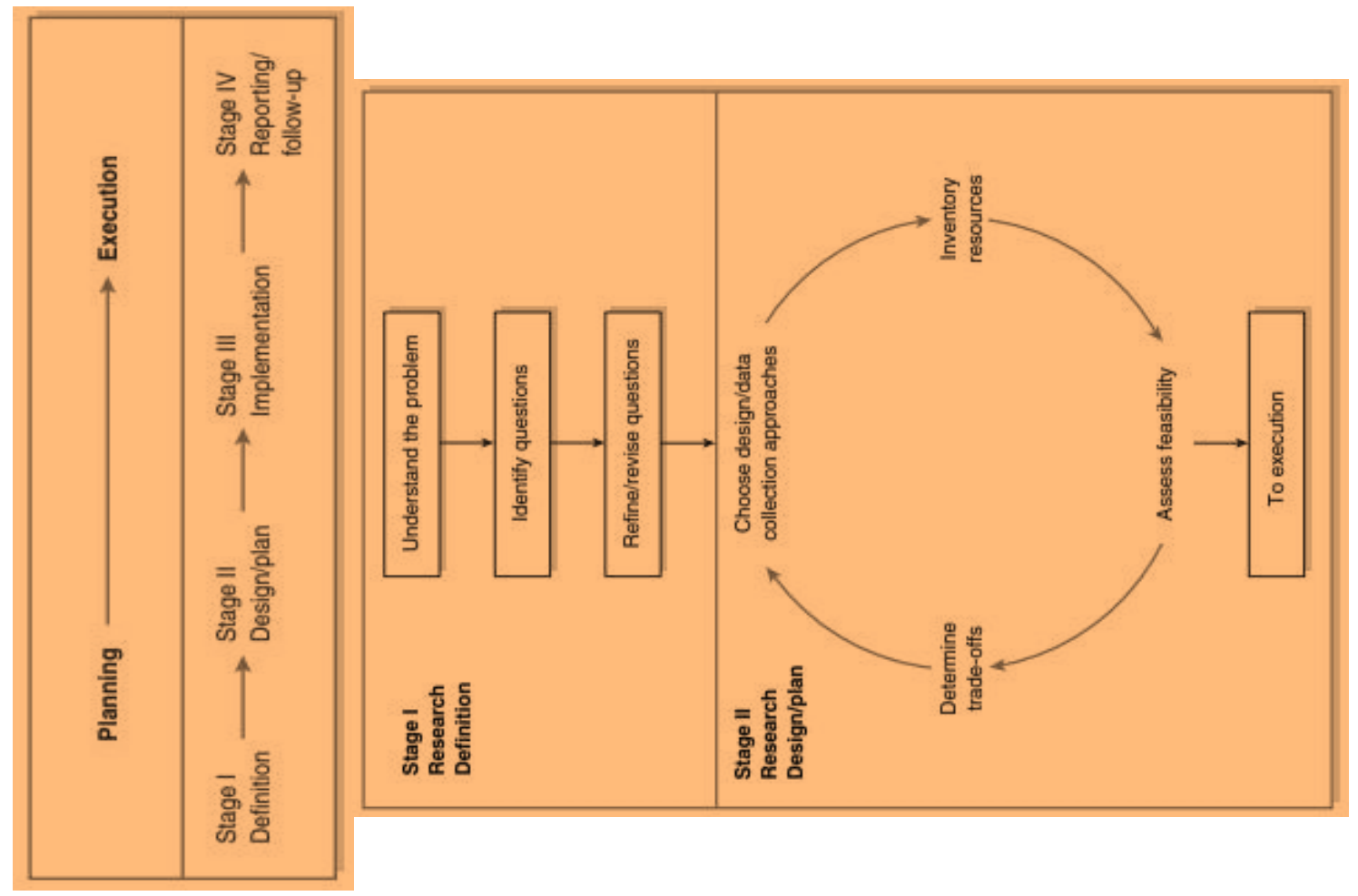

Figure

Note: Planning and Developing Applied Research for Social Field. Reprinted from Applied Research Design: A Practical Approach (pp. 3-43) by Bickman, L., and Rog, D., 2009, Sage. Copyright 2009 by Sage. Reprinted with permission.

However, Niiniluoto (1993) agrees that the nature of applied research is similar to that of basic research, but the ontology and axiology of both research kinds are fundamentally different, allowing for the following distinction:

\footnotetext{
${ }^{1}$ https://www.lifepersona.com/applied-research-characteristics-definition-examples
} 
The distinction between basic and applied research is notoriously vague, despite its frequent use in science studies and in science policy. In most cases it is based on such pragmatic factors as the knowledge and intentions of the investigator or the type of research institute. Sometimes the validity of the distinction is denied altogether. This paper suggests that there are two ways of distinguishing systematically between basic and applied research: (i) in terms of the "utilities" that define the aims of inquiry, and (ii) by reference to the structure of the relevant knowledge claims. An important type of applied research aims at results that are expressed by "technical norms" (in von Wright's sense): if you wish to achieve A, and you believe you are in a situation B, then you should do X. This conception of "design sciences" allows us to re-evaluate many issues in the history, philosophy, and ethics of science. (p. 1)

The distinction between basic and applied research is based on previous literature (Dudovskiy, 2011). It can be inferred that the significant distinctive of both are seen directly to "purpose, context, and method". But to intensify the knowledge applied, the additional information can be accessed on the succeeding note. ${ }^{234}$

\section{Conclusion}

Finally, I may state that a research framework based on a research philosophy including positivism, post-positivism, and criticism is the theoretical underpinning of research thinking. Basic, applied, and development research in all types of practical research. As a result, applied research is one degree forward of prior knowledge acquisition; knowledge in nature be created, tested, rebuilt, and found by scientific agents who are liable to account for the sustainability of knowledge acquisition. On the one hand, problems or gaps are emerging to disrupt humanity and the universe constantly; The COVID19 dilemma is forcing people to determine alternatives to identify superfluous changes. While, applied research, in addition to research and development, is a scientific method that promotes the preservation of existence's equilibrium. This method is a high priority approach for prevailing knowledge studies.

\section{References}

Bickman, L., \& Rog, D. (2009). Applied Research Design: A Practical Approach. In L. Bickman \& D. J. Rog (Eds.), The SAGE Handbook of Applied Social Research Methods (pp. 3-43). Sage. https://doi.org/10.4135/9781483348858.n1

Blog, F. (2022, May 7). What is Applied Research? + [Types, Examples \& Method]. Https. https://www.formpl.us/blog/applied-research

Dudovskiy, J. (2011). Applied Research - Research-Methodology. Research-Methodology; BRM. https://research-methodology.net/research-methodology/researchtypes/applied-research/

Edgar, T. W., \& Manz, D. O. (2017). Chapter 3 - Starting Your Research. ScienceDirect, $63-$ 92. https://www.sciencedirect.com/science/article/pii/B9780128053492000030

\footnotetext{
${ }^{2}$ https://examples.yourdictionary.com/examples-of-applied-research.html

${ }^{3} \mathrm{https} / / / \mathrm{psychologywithmisssmith.wordpress.com/model-answers-applied-psychology/}$

${ }^{4} \mathrm{https} / / /$ psychcentral.com/blog/understanding-research-methodology-5-applied-and-basic-research\#1
} 
Edgar, T. W., Manz, D. O., Edgar, T. W., \& Manz, D. O. (2017). Chapter 11Applied Experimentation. In Research Methods for Cyber Security (pp. 271-297). Syngress. https://doi.org/https://doi.org/10.1016/B9780128053492.00011X

Hale, J. (2011, May 12). Understanding Applied and Basic Research. Psych Central. https://psychcentral.com/blog/understanding-research-methodology-5-applied-andbasic-research\#1

Khan, R. (2021). Various Types and Characteristics of Applied Research. 9(1), 1-2. Journal of Research and Development. https://www.longdom.org/open-access/various-typesand-characteristics-of-applied-research-86598.html

lifepersona. (2022). Applied research: characteristics, definition, examples. Life Persona. https://www.lifepersona.com/applied-research-characteristics-definition-examples

Niiniluoto, I. (1993). The aim and structure of applied research. Erkenntnis, 38(1), 1-21. https://doi.org/10.1007/bf01129020

Smith. (2017, February 8). Model Answers - Applied Psychology. Miss Smith Has Got Your Back! https://psychologywithmisssmith.wordpress.com/model-answers-appliedpsychology/

YourDictionary. (2014, January 17). Examples of Applied Research Topics. YourDictionary. https://examples.yourdictionary.com/examples-of-applied-research.html 